\title{
Incidents of harm in European drinking environments and relationships with venue and customer characteristics
}

\author{
Zara Quigg ${ }^{1}$, Karen Hughes ${ }^{1}$, Mark A. Bellis ${ }^{2}$, Ninette van Hasselt ${ }^{3}$, Amador Calafat ${ }^{4}$, Matej Košir ${ }^{5}$, \\ Mariangels Duch ${ }^{4}$, Montse Juan ${ }^{4}$, Lotte Voorham ${ }^{3}$, and Ferry X. Goossens ${ }^{3}$ \\ ${ }^{1}$ Centre for Public Health, Liverpool John Moores University, Liverpool, UK \\ ${ }^{2}$ Public Health Wales, Cardiff, UK \\ ${ }^{3}$ Trimbos-instituut, Utrecht, Netherlands \\ ${ }^{4}$ European Institute of Studies on Prevention (IREFREA), Palma de Mallorca, Spain \\ ${ }^{5}$ Institute for Research and Development ‘Utrip’, Ljubljana, Slovenia
}

\begin{abstract}
Aim: Research shows there are associations between bar environments and alcohol-related harms. However, few European studies have examined such links. Our study investigates the type of harms experienced by patrons in European bars, and their relationships with individual, social and environmental factors.

Design: Unobtrusive one-hour observational visits. Characteristics of the bar environment, staff and patrons, and harms observed were recorded on structured schedules.

Setting: Bars in four cities in the Netherlands, Slovenia, Spain and the United Kingdom (U.K.).

Participants: 238 observations across 60 bars.

Measures: Analyses utilized chi-squared, analyses of variance and logistic regression.

Findings: 114 incidents of harm were observed; in one-fifth of visits, at least one incident was recorded. People falling over, arguing or being so severely intoxicated that they required assistance to walk were the most common incidents observed. Bivariate analyses showed associations between a range of staffing, customer and environmental characteristics, and incidents of harm. Controlling for city and venue, only a permissive environment remained significant in multivariate analyses.

Conclusions: Harms occurring in nightlife venues are typically minor. However, such incidents have the potential to escalate into more serious harms; thus, prevention is crucial. Prevention should focus on improving venue management practice and on the behavioral standards expected of customers.
\end{abstract}

Nightlife settings are known to be common locations for alcohol-related harms, including physical and verbal aggression, drunkenness and unintentional injury (Hughes, Anderson, Morleo, \& Bellis, 2008; Luke et al., 2002; Schnitzer et al., 2010). Research on alcohol-related harms in nightlife environments across Europe is rare, but there have been a few studies which have indicated the extent of such harms. A study of 16- to 35-year-olds in nine European cities found that the proportion of participants who reported involvement in violence in nightlife in the past 12 months ranged from 7.5\% in Ljubljana, Slovenia, to 29.1\% in Berlin, Germany (Schnitzer et al., 2010). In their study into nightlife drinking behaviors in young people across four European cities, Hughes et al. (2011a) found that over $60 \%$ of participants expected to binge drink on the night of survey.

Alcohol-related harms occurring within nightlife venues that come to the attention of authorities tend to involve more serious outcomes, such as violence (Luke et al., 2002). However, more minor incidents that are often accepted or unreported, such as patrons arguing or being too drunk to walk (Hesse, Tutenges, Pedersen, \& Kofoed, 2012; Hughes et al., 2008; Tutenges, 2012), have the potential to escalate into more serious problems, including violence and unintentional injury. Research shows that a large proportion of alcohol-related problems in nightlife are often focused around a small number of venues (Briscoe \& Donnelly, 2003; Newton \& Hirschfield, 2009), suggesting

Correspondence: Zara Quigg, Centre for Public Health, Liverpool John Moores University, Henry Cotton Building, 15-21 Webster Street, Liverpool L3 2ET, UK, Telephone: +44 (0)151 231 4511. Fax: +44 (0)151 231 4552. Email: z.a.quigg@ljmu.ac.uk

Financial support: The research leading to these results has received funding from the European Community's Seventh Framework Programme (FP7/2007-13) under grant agreement no.223 059-Alcohol Measures for Public Health Research Alliance (AMPHORA).

Keywords: Alcohol, harm, nightlife, prevention 
that certain factors about these venues may impact on patrons' experience of harms. A wide range of individual, social and environmental factors have been shown to contribute to alcohol-related harm in nightlife venues. These include a permissive environment, cheap alcohol availability, poor cleanliness, crowding, loud music, a focus on dancing, and poor staff practice (Hughes et al., 2011b). Most of this research, however, has been conducted in North America (Graham et al., 2004) and Australia (Homel, Carvolth, Hauritz, McIlwain, \& Teague, 2004).

Findings from studies on the bar environment have facilitated the development of interventions to reduce alcohol use and related harm (e.g., staff training in Canada (Graham et al., 2004), and codes of practice for drinking venues in Australia (Homel, Hauritz, Wortley, McIlwain, \& Carvolth, 1997)), which have been associated with observed reductions in alcohol-related outcomes in venues where the interventions were implemented (Graham et al., 2004; Homel et al., 1997). Similar prevention measures have been implemented in some European countries (Hughes, Furness, Jones, \& Bellis, 2010; Mansdotter, Rydberg, Wallin, Lindholm, \& Andréasson, 2007). However, as there has been limited research on the type and extent of harms occurring within European nightlife venues and on the relationships of these harms to individual, social and environmental factors, little is known about how relevant international research findings are to Europe. To address this gap, we undertook a quantitative observational study in youth-focused bars in four European cities.

\section{Methods}

The study took place in four European cities: Liverpool, U.K.; Ljubljana, Slovenia; Palma de Mallorca, Spain; and Utrecht, the Netherlands (for further information on each city, see Hughes et al., 2011a). Sixty venues were identified for inclusion in the study, 15 within each study site. In Liverpool, Ljubljana, and Utrecht, a list of all youth-focused bars (identified through consultation with local authorities, and based on research knowledge of the nighttime economy) in the main nightlife area(s) of each city were obtained from local police or other relevant authorities. Bars were then categorized into low, medium or high-risk premises, based on local intelligence of alcohol-related harm. From each sub-group of venues, five premises were randomly selected for inclusion in the study. In Palma, low, medium and high-risk venues for inclusion in the study were selected based on consultation with local nightlife users.

Two research tools were used: an observation schedule to assess the premises (see Hughes et al., 2012) and an incident form to record details of incidents of harm witnessed during visits. Both tools were based on those used by Graham et al. (2006) in Canada (see http://publish.uwo.ca/ kgraham/safer_bars.html). The schedule included a range of scale variables and other questions covering these factors: the venue entrance (e.g., whether door staff were present); the bar environment (e.g., cleanliness); bar activities (e.g., dancing); alcohol and food service; customer type (e.g., young clientele) and behaviors (e.g., level of dancing); and staffing characteristics (e.g., male) and behaviors (e.g., attitude). For all scale variables, the schedule specified the scale range (e.g., level of intoxication among customers in the venue ranged from $0=$ no sign of intoxication, to $9=$ everyone is drunk). The observational schedule allowed researchers to record the number of incidents of harm they observed among customers and/or staff from a pre-selected list (e.g., someone falling over drunk), with an option to record other harms unlisted. For each incident observed, researchers were requested to complete a separate incident form to record details of the circumstances of the incident and the individuals involved (data not reported here). To ensure consistency in implementing the study and completing the schedule and incident forms, research coordinators from each study site undertook a training session. The training included a test bar observation, with research coordinators completing the schedule (and incident forms if necessary) independently after the visit and comparing and discussing ratings at a meeting the following day. The training program was then repeated by research coordinators, in their respective countries, with recruited field researchers (see Hughes et al., 2011a; 2012).

In each venue, unobtrusive one-hour observational visits were undertaken during peak opening hours, on four separate occasions, by a mixed-gender pair. To ensure observations were based on natural behaviors, staff and patrons within venues were not informed that they were being observed. The exact hours of study varied from city to city depending upon local nightlife activity, but all visits took place on Thursday, Friday, and Saturday nights (September to December 2010) between 10 p.m. and 5 a.m. A total of 238 visits were undertaken (two of the premises were visited three, rather than four, times). Field researchers were instructed to behave as customers during visits (wearing clothing appropriate to the venue) and avoid interaction with other customers wherever possible; they were permitted to consume one alcoholic drink per visit. Researchers were instructed to independently complete the observational schedule and any incident forms following each visit, after leaving the venue. Covert note taking was permitted (e.g., on mobile phones) during the visit. During the following week, research coordinators held a meeting with fieldworkers in which paired schedules were checked against each other, and differences between them were discussed and resolved. Thus, each visit resulted in a single completed schedule. Incident forms were assessed for completeness and, where possible, further details obtained. Ethical approval for the study was obtained from the research ethics committee at Liverpool John Moores University in the U.K.

Data from all four cities were entered into SPSS version 17 for analysis. An additional variable (the primary dependent variable) was derived to indicate whether any incidents among customers or staff had been witnessed during the visit. Data completeness was high (> 98\%) across all variables except individual drink prices (only $67 \%$ of visits 
provided all four drink prices asked for, although 98\% had at least one drink price recorded). Missing values were imputed as the city mean for scale variables, or the venue norm for dichotomous variables. Bivariate analyses utilized chi-squared $\left(X^{2}\right)$ and analyses of variance (ANOVA). Backward conditional logistic regression was used to identify which staffing, customer and environmental characteristics of bars were independently associated with incidents of harm. Prior to adding significant variables from the bivariate analyses into the model, all scale variables were correlated. The following variables were identified as highly correlated ( $\mathrm{r}>0.6)$ : sexual activity/sexual competition $(r=0.77)$; crowdedness/movement ( $r=0.69)$; and seating/dancing $(r$ $=0.62$ ). These variables were combined, standardized, and added to the model with all other significant variables from the bivariate analyses, along with a venue code (i.e., a unique identifier assigned to each venue) to control for repeated visits.

\section{Results}

In total, 238 visits were completed in 60 bars across four cities. One hundred and fourteen incidents were observed (see Table 1 for examples of incident descriptions); 34.2\% in Ljubljana, 32.4\% in Liverpool, 30.7\% in Utrecht and $2.6 \%$ in Palma. At least one incident was observed in over a third (35.0\%) of visits in Liverpool, $25.0 \%$ of visits in Ljubljana, $20.7 \%$ of visits in Utrecht, and $3.3 \%$ of visits in Palma $\left(X^{2}[3]=18.95, p<.001\right)$. Overall, $48.3 \%$ of all venues had at least one visit where an incident was observed (i.e., over typically four hours of observation). The majority (94.7\%) of incidents observed were among customers, with the remainder among staff. Overall, falling over accounted for the highest proportion (10.1\%) of incidents observed and was the most commonly recorded harm in Liverpool (23.3\%; $\left.X^{2}[3]=20.05, p<.001\right)$. Arguing (8.8\%) was the next most common incident observed (and the most common recorded in Ljubljana and Utrecht; $13.3 \%$ and $12.1 \%$ respectively; $X^{2}[3]=8.19, p<$ .05 ), followed by being so severely intoxicated that assistance was required (e.g., to walk) (5.0\%).

Table 1

Examples of observer descriptions of incidents

Incident category ${ }^{\mathrm{a}}$ and example description

Falling over: "A female (aged 18) was dancing provocatively around a pole (dancing pole, on a stage area) and a banister (surrounding the stage) that were on a raised dance floor/stage area. She was very drunk and fell to the floor, lying there for about 30 seconds laughing. She then got back up and carried on dancing on the pole. She had no injuries and there was no reaction from the people surrounding her (>10 people) or door staff who were standing close by."

Arguing: "Two males (aged 45 years) and two females (aged 42 and 40) were leaving the bar. One female pushed one of the males and shouted 'fuck off' at him. The door staff were watching but they laughed and did not do anything. Outside the woman said something angry at the male again. They looked like couples. Reason for argument or how it ended not known.”

Too intoxicated to walk without assistance: "When we entered the venue (bar) we saw a young male (beginning of his twenties) being carried out by his friends and a member of the staff. When they arrived at the bottom of the stairs which led outside, the friends told the staff member that they would take care of him. When the staff member released the man, he immediately fell on the ground. His friends managed to get him up the stairs with great effort and put him on a bench outside. We were not able to determine whether the man sustained any injuries.”

Pushing or grabbing someone else in an aggressive manner: "Four bouncers (door staff) who had been standing by the front entrance ran through the bar heading towards the toilets (reason unknown). There were only 20 people in the bar at this point. Although there was plenty of room, the bouncers ran through a group of people (three males and three females, all under 21 years) and pushed them aggressively out of their way, telling them to move! A number of drinks were dropped and smashed on the floor and drinks were spilt over the group. The group just looked amazed and shocked by what had happened. They were not that drunk."

Vomiting: “A male patron about 35-40 years old is leaning on the men's bathroom door calling at somebody inside but observer is unable to understand the words. Nobody from the staff pays attention to it. There are a lot of people moving around. Suddenly the male bends over on the closer bar counter and vomits on the floor. He stays there for a while and then leaves. Nobody from the bar (staff or patrons) has noticed anything.”

\footnotetext{
${ }^{a}$ List of all types of incidents of harm used in analyses: falling over; arguing; too intoxicated to walk without assistance; pushing or grabbing someone else in an aggressive manner; vomiting; threatening a person/group of people (including with a weapon); hitting someone else; a physical fight; throwing something in anger at someone; and injuring themselves.
}

Tables 2 and 3 show a range of recorded staffing, customer and environmental characteristics of bars, in relation to whether or not an incident was observed during a visit (additional analyses of the distribution of bar characteristics by city of visit, and the characteristics' relationship with intoxication, are provided elsewhere (Hughes et al., 2012)). Significant associations were seen between observed incidents and most customer-focused characteristics (excluding male clientele, young clientele and highalcohol-content drinks). For staff characteristics, younger staff (more than $50 \%$ thought to be under the age of 25 years) and higher levels of permissiveness were associated with incidents. Physical characteristics associated with incidents included lower proportions of seating, higher 
levels of crowdedness, the presence of glass on the floor, and toilets that had poor levels of cleanliness. Alcoholic drink promotions were associated with incidents. The playing of rock/heavy music was associated with no incidents being observed. Of the four contextual variables analyzed (city, visit time, number of customers in the premise, and whether the venue had an outdoor drinking area), only city showed an association with any incidents being observed. Logistic regression analysis was used to identify which staffing, customer and environmental characteristics of bars were independently associated with incidents being observed. Here, controlling for city and venue, in the final model only one variable remained: permissiveness (Adjusted Odds Ratio $[A O R]=1.5$; $p<$ $.01)$.

Table 2

Percentage of visits recording environmental factors, and mean ratings for environment-related scales, by whether at least one incident was observed or not

\begin{tabular}{|c|c|c|c|c|}
\hline \multirow[b]{2}{*}{ Variable } & \multirow{2}{*}{$\begin{array}{c}\text { No incidents } \\
\% / \text { mean }\end{array}$} & \multicolumn{3}{|c|}{ Incidents observed } \\
\hline & & $\% /$ mean & $X^{2} / \mathbf{f}$ & $P$ \\
\hline \multicolumn{5}{|l|}{ Contextual variables } \\
\hline Later visit & $46.8 \%$ & $62.0 \%$ & 3.65 & ns \\
\hline$>100$ customers & $57.4 \%$ & $68.0 \%$ & 1.83 & ns \\
\hline Outdoor drinking area & $58.0 \%$ & $68.0 \%$ & 1.65 & $n s$ \\
\hline \multicolumn{5}{|l|}{ Entry to the bar } \\
\hline Door staff & $80.3 \%$ & $86.0 \%$ & 0.85 & $n s$ \\
\hline Queue & $21.8 \%$ & $30.0 \%$ & 1.47 & ns \\
\hline Entrance fee & $20.7 \%$ & $32.0 \%$ & 2.82 & ns \\
\hline House rules (entry) & $30.3 \%$ & $38.0 \%$ & 1.07 & ns \\
\hline \multicolumn{5}{|l|}{ Physical environment } \\
\hline Seating & 5.9 & 7.1 & 7.43 & $* *$ \\
\hline Noise & 5.9 & 6.0 & 0.52 & $n s$ \\
\hline Crowding & 4.1 & 5.2 & 10.8 & $* *$ \\
\hline Ventilation & 2.9 & 3.0 & 0.03 & $n s$ \\
\hline Temperature & 4.6 & 4.8 & 0.51 & $n s$ \\
\hline Clearing & 5.1 & 5.4 & 0.50 & $n s$ \\
\hline Glass on floor & 1.7 & 3.1 & 17.13 & $* * *$ \\
\hline Cleanliness & 4.7 & 5.2 & 2.07 & ns \\
\hline Toilets & 3.7 & 4.5 & 5.18 & $*$ \\
\hline Lighting & 3.4 & 3.6 & 0.71 & $n s$ \\
\hline \multicolumn{5}{|l|}{ Bar activities } \\
\hline Dance floor & $58.0 \%$ & $70.0 \%$ & 2.39 & ns \\
\hline Pool tables & $6.9 \%$ & $4.0 \%$ & 0.57 & $n s$ \\
\hline TV screens & $53.2 \%$ & $62.0 \%$ & 1.24 & $n s$ \\
\hline House rules (inside) & $29.3 \%$ & $30.0 \%$ & 0.01 & ns \\
\hline Rock/heavy music & $18.6 \%$ & $6.0 \%$ & 4.69 & $*$ \\
\hline Rap/hip hop music & $21.8 \%$ & $28.0 \%$ & 0.85 & $n s$ \\
\hline Pop/dance music & $73.4 \%$ & $76.0 \%$ & 0.14 & $n s$ \\
\hline \multicolumn{5}{|l|}{ Alcohol and food service } \\
\hline Alcoholic drink promotions & $23.4 \%$ & $38.0 \%$ & 4.32 & $*$ \\
\hline Low drink prices & $56.9 \%$ & $44.0 \%$ & 2.65 & $n s$ \\
\hline Soft drink promotions & $16.0 \%$ & $10.0 \%$ & 1.12 & $n s$ \\
\hline Table service & $28.7 \%$ & $28.0 \%$ & 0.01 & $n s$ \\
\hline Food service & $8.5 \%$ & $4.0 \%$ & 1.15 & ns \\
\hline
\end{tabular}

Bivariate analyses of categorical and continuous variables utilize $\mathrm{X}^{2}$ and ANOVA. $n s=$ not significant; $* P<.05 ; * * P<.01$; $* * * P<.001$. 
Table 3

Percentage of visits recording staffing and customer factors, and mean ratings for staffing and customer-related scales, by whether at least one incident was observed or not

\begin{tabular}{|c|c|c|c|c|}
\hline \multirow[b]{2}{*}{ Variable } & \multirow{2}{*}{$\begin{array}{c}\text { No incidents } \\
\% / \text { mean } \\
\end{array}$} & \multicolumn{3}{|c|}{ Incidents observed } \\
\hline & & $\% /$ mean & $X^{2} / \mathbf{f}$ & $P$ \\
\hline \multicolumn{5}{|l|}{ Bar staff } \\
\hline Fewer bar staff & $35.1 \%$ & $28.0 \%$ & 0.89 & ns \\
\hline Young staff & $34.0 \%$ & $50.0 \%$ & 4.30 & $*$ \\
\hline Male staff & $50.5 \%$ & $58.0 \%$ & 0.88 & $n s$ \\
\hline Glass collectors & $51.6 \%$ & $62.0 \%$ & 1.72 & $n s$ \\
\hline Staff monitoring & 3.2 & 3.1 & 0.03 & ns \\
\hline Staff coordination & 4.5 & 4.1 & 1.92 & ns \\
\hline Staff attitude & 2.1 & 2.1 & 0.04 & $n s$ \\
\hline Staff boundaries & 2.5 & 2.2 & 0.72 & ns \\
\hline Permissiveness & 1.7 & 3.0 & 25.6 & $* * *$ \\
\hline \multicolumn{5}{|c|}{ Customer type and behaviors } \\
\hline Male clientele & $71.8 \%$ & $64.0 \%$ & 1.15 & $n s$ \\
\hline Young clientele & $14.4 \%$ & $22.0 \%$ & 1.72 & ns \\
\hline Single sex groups & $50.0 \%$ & $66.0 \%$ & 4.06 & $*$ \\
\hline High alcohol drinks & $47.3 \%$ & $40.0 \%$ & 0.86 & $n s$ \\
\hline Dancing & 3.7 & 5.2 & 8.86 & $* *$ \\
\hline Sexual activity & 2.7 & 3.7 & 9.79 & $* *$ \\
\hline Sexual competition & 2.4 & 3.6 & 13.46 & $* * *$ \\
\hline Intoxication & 3.6 & 4.6 & 13.71 & $* * *$ \\
\hline Movement & 4.4 & 5.2 & 5.74 & $*$ \\
\hline
\end{tabular}

Bivariate analyses of categorical and continuous variables utilize $\mathrm{X}^{2}$ and ANOVA. $n s=$ not significant; ${ }^{*} P<.05$; ** $P<.01$; $* * * P<.001$

\section{Discussion}

In recent years, studies identifying the type and extent of harms experienced by young nightlife users across Europe have started to emerge (Hughes et al., 2008; 2011a; Schnitzer et al., 2010; Tutenges, 2012). While studies in Scotland (Forsyth, 2006; Forsyth, Cloonan, \& Barr, 2005) have assessed the relationships between observed aggression and recorded crime within nightlife venues and individual, social and environmental factors, to our knowledge this is the first observational study to examine a range of harms within venues and their links with staffing, customer and environmental characteristics across multiple European cities. Our study shows that a fifth of all visits had at least one recorded incident of harm, with a total of 114 incidents observed in 238 visits. This equates to just under one incident observed in every two hours of observation (though some minor incidents may have gone unobserved). A larger Canadian study by Graham et al. (2004), which focused on aggression rather than any type of alcohol-related harm, reported similar levels of observed harm in study venues (just over one incident in every three hours of observation), yet a study by Forsyth et al. (2005) in Scotland, again focusing on aggression in bars, reported much lower levels (one incident in every seven hours of observation).

The most commonly observed harms in our study venues included people falling over, arguing and being too intoxicated to walk without assistance. Although we observed venues during peak times, and included venues known to experience alcohol-related harms, few severe incidents (e.g., fighting, injuries) were observed. Although minor incidents, such as those observed here, will impact upon nightlife patrons and the nighttime environment, they may not come to the attention of authorities such as the police. However, preventing minor incidents will inevitably have an impact on avoiding, and thus reducing, more serious incidents. Further research should explore the types and severity of incidents identified and reported through different means to obtain a greater understanding of the extent and nature of harms experienced across European nightlife settings. Equally, addressing the question of whether harms are more likely to occur within venues or outside is crucial to developing and focusing future research. In a U.K study of nightlife users (Anderson, Hughes, \& Bellis, 2007), more participants reported having being involved in, or witnessing, a physical fight in the streets surrounding nightlife venues than inside 
venues. In fact, it has been suggested that when problems (e.g., intoxicated patrons) occur inside venues, security staff may move them outside the venue, to reduce the likelihood of the venue being associated with alcoholrelated harms (Scott \& Didel, 2006).

Our study found alcohol-related harms were concentrated in just under half of all study venues. As suggested by other research, certain factors within a small number of bars and nightclubs can mean that alcohol-related problems such as violence are concentrated in those premises (Briscoe \& Donnelly, 2003; Newton \& Hirschfield, 2009); altering these factors can reduce or increase the risks of alcohol-related harms. Similar to other research (Graham et al., 2004; 2006), our bivariate analyses identified a wide range of staffing, customer and environmental factors that were significantly associated with incidents of harm, such as glass on the venue floor, a permissive environment, and high levels of intoxication amongst patrons. Within the final logistic regression model, however, only one factor remained significant: a permissive environment. The links between a permissive environment and aggression and intoxication in nightlife venues have been identified elsewhere (Graham et al., 2006; Hughes et al., 2012). Our findings support such research and suggest that while a broad suite of measures that aim to prevent alcohol-related harm may be needed (Calafat, Duch, Juan, \& Leckenby, 2012), activity should specifically focus on improving management practices and on the behavioral standards expected of customers in European nightlife venues.

Our study has some limitations. As with all cross-sectional surveys, results do not establish cause and effect. Thus, we cannot ascertain causal relationships between bar and customer characteristics and incidence of harm. However, our findings do identify characteristics that may increase the risk of incidents of harm occurring in nightlife venues, and this intelligence can inform prevention measures. Our study may also have been affected by structural and cultural inconsistencies across the four countries, such as differences in licensing legislation or in researcher interpretation of the observational measures and what constitutes harm in nightlife (despite the detailed training program the researchers received). While the use of the same researchers across all four countries would have improved the likelihood of our study being implemented consistently, this would be logistically complicated. Our study did not aim to compare the extent of harms experienced across the four countries, but the number recorded in each country varied widely, with Palma reporting the lowest levels. Further research exploring the reasons behind Palma's comparatively low levels of observed harm is needed, and may help identify ways to prevent harm within nightlife venues. Such research is particularly important given the perceived convergence of drinking patterns across Europe, particularly among young people (Anderson \& Baumberg, 2006; Hibell et al., 2009; Jarvinen \& Room, 2007). Further, across all countries, few incidents were recorded involving staff. Data presented in our study are based on observations made in environments that were often dark and busy; as such, field researchers may have missed some incidents, such as occurrences among staff who were out of sight (e.g., behind bar counters). Finally, while for most countries (excluding Palma) we randomly selected bars for inclusion in the study, the venues selected were not, nor were they intended to be, representative of each city. The sample was designed only to explore venues popular with young people in each city.

\section{Conclusion}

Our study illustrates the types of harms occurring in European nightlife settings. Few severe incidents (e.g., violence) were seen; observed harms were typically minor, such as patrons falling over, arguing, and being too drunk to walk. However, such incidents have the potential to escalate into more serious harms and will inevitably impact upon nightlife patrons, nightlife environments, and local services, such as health and criminal justice. Preventing such incidents is therefore important. With incidents of harm more likely to occur in permissive environments, prevention should focus on improving management practice, including staff expectations regarding the behavioral standards of customers.

\section{Acknowledgements}

We would like to thank all the researchers who assisted with the study implementation, particularly Sara Wood, Adam Caris, Steve Duggan, Lindsay Eckley, Ian Wood, Sanela Talić, Mirela Brkić, Joanne van der Leun, Cristina Gelabert, Marc Riera, Noelia Martínez, Rafael Umbert, and Joan Recasens.

\section{References}

Anderson, Z., Hughes, K., \& Bellis, M. A. (2007). Exploration of young people's experience and perceptions of violence in Liverpool's nightlife. Liverpool, UK: Centre for Public Health, Liverpool John Moores University.

Briscoe, S., \& Donnelly, N. (2003). Problematic licensed premises for assault in inner Sydney, Newcastle, and Wollongong. Australian and New Zealand Journal of Criminology, 36(1), 18-33.

Calafat, A., Duch, M., Juan, M., \& Leckenby, N. (2012). Health and safety European standards for nightlife venues. Adicciones, 24(4), 355-364.

Forsyth, A. J. M. (2006). Assessing the relationships between late night drinks marketing and alcoholrelated disorder in public space. Glasgow, Scotland: Glasgow Caledonian University.

Forsyth, A. J. M., Cloonan, M., \& Barr, J. (2005). Factors associated with alcohol-related problems within licensed premises. Glasgow, Scotland: Glasgow Caledonian University/ University of Glasgow.

Graham, K., Bernards, S., Osgood, D. W., \& Wells, S. (2006). Bad nights or bad bars? Multilevel analysis of environmental predictors of aggression in late-night large-capacity bars and clubs. Addiction, 101(11), 1569-1580. 
Graham, K., Osgood, D. W., Zibrowski, E., Purcell, J., Gliksman, L., Leonard, K., . . . Toomey, T. L. (2004). The effect of the Safer Bars programme on physical aggression in bars: Results of a randomized controlled trial. Drug and Alcohol Review, 23(1), 31-41.

Hesse, M., Tutenges, S., Pedersen, M. U., \& Koford, P. B. (2012). An exploratory prospective study of young people's drinking during a holiday. Nordic Studies on Alcohol and Drugs, 29(5), 485-496.

Homel, R., Carvolth, R., Hauritz, M., McIlwain, G., \& Teague, R. (2004). Making licensed venues safer for patrons: What environmental factors should be the focus of interventions? Drug and Alcohol Review, 23(1), 19-29.

Homel, R., Hauritz, M., Wortley, R., McIlwain, G., \& Carvolth, R. (1997). Preventing alcohol-related crime through community action: The Surfers Paradise Safety Action Project. In R. Homel, (Ed.), Policing for prevention: Reducing crime, public intoxication and injury (pp. 35-90). Monsey, NY, United States: Criminal Justice Press.

Hughes, K., Anderson, Z. A., Morleo, M., \& Bellis, M. A. (2008). Alcohol, nightlife and violence: The relative contributions of drinking before and during nights out to negative health and criminal justice outcomes. Addiction, 103(1), 60-65.

Hughes, K., Furness, L., Jones, L., \& Bellis, M. A. (2010). Reducing harm in drinking environments: Evidence and practice in Europe. Liverpool, England: Centre for Public Health, Liverpool John Moores University.

Hughes, K., Quigg, Z., Bellis, M. A., Calafat, A., van Hasselt, N., Košir, M., . . . Juan, J. (2012). Drunk and disorganised: Relationships between bar characteristics and customer intoxication in European drinking environments. International Journal of Environmental Research and Public Health, 9(11), 4068-4082. doi:10.3390/ijerph9114068

Hughes, K., Quigg, Z., Bellis, M. A., van Hasselt, N., Calafat, A., Košir, M., . . . Voorham, L. (2011a). Drinking behaviours and blood alcohol concentration in four European drinking environments: A crosssectional study. BMC Public Health, 11, 918. doi:10.1186/1471-2458-11-918

Hughes, K., Quigg, Z., Eckley, L., Bellis, M. A., Jones, L., Calafat, A., . . . van Hasselt, N. (2011b). Environmental factors in drinking venues and alcoholrelated harm: The evidence-base for European intervention. Addiction, 106(1), 37-46. doi: 10.1111/j.1360-0443.2010.03316.x.

Luke, L. C., Dewar, C., Bailey, M., McGreevy, D., Morris, H., \& Burdett-Smith, P. (2002). A little nightclub medicine: The healthcare implications of clubbing. Emergency Medicine Journal, 19, 542-545. doi:10.1136/emj.19.6.542

Mansdotter, A. M., Rydberg, M. K., Wallin, E., Lindholm, L. A., \& Andréasson, S. (2007). A cost-effectiveness analysis of alcohol prevention targeting licensed premises. European Journal of Public Health, 17(6), 618-623. doi:10.1093/eurpub/ckm017

Newton, A., \& Hirschfield, A. (2009). Measuring violence in and around licensed premises: The need for a better evidence base. Crime Prevention and Community Safety, 11(3), 171-188. doi:10.1057/cpcs.2009.12

Schnitzer, S., Bellis, M. A., Anderson, Z., Hughes, K., Calafat, A., Juan, M., \& Kokkevi, A. (2010). Nightlife violence-a gender-specific view on risk factors for violence in nightlife settings: A cross-sectional study in nine European countries. Journal of Interpersonal Violence, 25(6), 1094-1112.

Scott, M. S., \& Didel, K. (2006). Assaults in and around bars. 2nd Edition. Washington, DC, United States: U.S. Department of Justice Office of Community Oriented Policing Services.

Tutenges, S. (2012). Nightlife Tourism: A mixed methods study of young tourists at an international nightlife resort. Tourist Studies, 12(2), 131-150. doi:10.1177/1468797612454250 